\title{
Toward a Better Understanding of Dural Arteriovenous Fistula Angioarchitecture: Superselective Transvenous Embolization of a Sigmoid Common Arterial Collector
}

\author{
(D) M. Shapiro, (D) E. Raz, (D) M. Litao, (D)T. Becske, (D) Hiina, and (D).K. Nelson
}

\begin{abstract}
BACKGROUND AND PURPOSE: Our aim was to propose a conceptually new angioarchitectural model of some dural arteriovenous fistulas based on subset analysis of transverse and sigmoid type lesions. The "common collector" notion argues for convergence of multiple smaller caliber arterial vessels on a common arterial collector vessel within the sinus wall. Communication of this single collector (or constellation of terminal collectors) with the sinus proper defines the site of arteriovenous fistula, which can be closed by highly targeted embolization, preserving the sinus and avoiding unnecessary permeation of indirect arterial feeders.
\end{abstract}

MATERIALS AND METHODS: One hundred consecutive dural arteriovenous shunts were examined. Thirty-six transverse/sigmoid fistulas were identified within this group and analyzed for the presence of a common arterial collector as well as other parameters, including demographics, grade, treatment approach, and outcome.

RESULTS: A common collector was identified in nearly all Cognard type I lesions (15 fistulas with 14 single collector vessels seen) and progressively less frequently in higher grade fistulas. Identification of the common collector requires careful angiographic analysis, including supraselective and intraprocedural angiographies during treatment, and final embolic material morphology.

CONCLUSIONS: Detailed evaluation of imaging studies allows frequent identification of a vascular channel in the sinus wall, which we argue reflects a compound, common arterial channel (rather than a venous collector) with 1 or several discrete fistulous points between this vessel and the sinus proper. Targeted closure of this channel is often feasible, with sinus preservation and avoidance of embolic material penetration into arteries remote from fistula site.

ABBREVIATION: dAVF $=$ dural arteriovenous fistula

D ural arteriovenous fistulas (dAVFs) are pathologic arteriovenous shunts of the dural venous sinuses. Broad consensus exists regarding the relationship between the severity of dAVFrelated cerebral venous congestion and disease morbidity, as reflected in the grading scales of Borden et $\mathrm{al}^{1}$ and Cognard et al. ${ }^{2}$ In contrast, there is less agreement on the nature of the pathologic angioarchitecture composing these lesions; the identity of the various vascular components, arterial or venous, in proximity to the fistula; the number and location of shunts in relation to the dural sinus; and the underlying mechanisms driving the evolution and

Received January 31, 2018; accepted after revision June 6

From the Departments of Radiology (M.S., E.R., H.R., P.K.N.), Neurology (M.S., M.L.), and Neurosurgery (H.R., P.K.N.), NYU School of Medicine, New York, New York; and Department of Neurology (T.B.), Rochester Regional Health, Rochester, New York.

Please address correspondence to Maksim Shapiro, MD, Bernard and Irene Schwartz Interventional Neuroradiology Section, Center for Cerebrovascular Disease and Stroke, NYU Langone Medical Center, 660 First Ave, 7th floor, New York, NY 10016; e-mail: neuroangio@neuroangio.org; @neuroangiol; @neuroangio http://dx.doi.org/10.3174/ajnr.A5740

occasional spontaneous involution of untreated lesions. Various treatment methods, transarterial ${ }^{3,4}$ and transvenous, ${ }^{5,6}$ have been used with generally successful results. ${ }^{7,8}$ However, these treatments frequently lack target specificity, resulting in unnecessary permeation of arterial vessels remote from the site of shunting or sacrifice of venous structures likewise not directly involved in the shunt pathology. This article reviews the existing literature, which suggests that most transverse/sigmoid dAVFs consist of 1 or at most a limited number of direct arteriovenous connections. The seemingly complex angioarchitecture of these lesions is proposed to represent myriad artery-to-artery anastomoses, converging on a common collector vessel within the wall of the dural sinus. This collector, sometimes (we believe erroneously) referred to as a venous septation or pouch, in fact represents a final common arterial channel, with 1 opening (or a limited set of openings) into the dural sinus. The site of the fistulous communication thus involves a discrete point in the sinus wall where this common artery empties into the sinus, an arrangement best appreciated in lower grade fistulas. Highly targeted occlusion of this common channel and its 
Breakdown by Cognard type, hemorrhage status on presentation, and presence of a common collector channel

\begin{tabular}{lccc}
\hline $\begin{array}{c}\text { Cognard } \\
\text { Type }\end{array}$ & No. & $\begin{array}{c}\text { Hemorrhagic } \\
\text { Presentation (No.) }\end{array}$ & $\begin{array}{c}\text { Common } \\
\text { Channel (No.) (\%) }\end{array}$ \\
\hline 1 & 15 & 0 & $14(93 \%)$ \\
Ila & 12 & 0 & $5(42 \%)$ \\
IIb & 0 & 0 & NA \\
Ilab & 3 & 0 & $1(33 \%)$ \\
III & 6 & 4 & $2(33 \%)$ \\
\hline
\end{tabular}

Note:-NA indicates not applicable.

connection with the true sinus, when possible, minimizes collateral embolization with its associated hazards, procedural costs, and radiation dose.

\section{MATERIALS AND METHODS}

NYU Institutional Board Review approved retrospective review of 100 consecutive dural arteriovenous shunts presenting for endovascular treatment from 2009 until 2017 was conducted by M.L. and M.S. to identify a subset of transverse and sigmoid sinus fistulas. A detailed examination of preprocedural MR and CT crosssectional imaging and diagnostic and embolization angiographic studies was performed for evidence of the existence of a common arterial collector vessel and for assignment of fistula location by authors P.K.N., E.R., and M.S. Diagnostic angiography and embolization were performed on Axiom Artis or Q systems (Siemens, Erlangen, Germany) via femoral approach for both arterial and venous access at fluoroscopic and roadmap rates of 7.5 frames per second and digital subtraction angiography at 2 frames per second using the as low as reasonably achievable principles. Most diagnostic procedures were performed with the patient under local anesthesia, and all treatment was performed with the patient under general anesthesia. 3D-DSA was not acquired during diagnostic or therapeutic dAVF procedures. Data were also collected on the treatment strategy (arterial, venous, or both), number of treatment sessions, ultimate fistula status (closed or open), and any periprocedural complications, defined broadly as any new neurologic deficit or any delayed treatment-related neurologic issue. All authors were involved in performance of endovascular procedures. Fistulas in other locations were excluded from analysis at this stage.

\section{RESULTS}

Thirty-six patients (mean age, $56 \pm 14$ years; 17 women) with transverse/sigmoid sinus fistulas were identified. The Table shows the breakdown by Cognard ${ }^{2}$ type, hemorrhage status on presentation, and the presence of a common collector channel, which was identified in all but 1 of Cognard type I fistulas and progressively less frequently in higher grade lesions. A median of 1 embolization session (average, 1.47 sessions) was required to close $93 \%$ of fistulas by transarterial $(n=19)$, transvenous $(n=9)$, and combined $(n=8)$ approaches, incurring 1 permanent (lateral medullary infarct) and 1 transient (delayed venous sinus thrombosis resolved with anticoagulation) complication. Figures 1 and 2 illustrate normal and pathologic dAVF angioarchitecture according to a common collector theory and nonselective treatment approaches. The 2 cases shown in Figs 3-4 illustrate subselective transvenous embolization of the common collector vessels with coils (Fig 3) or $n$-BCA (Fig 4).

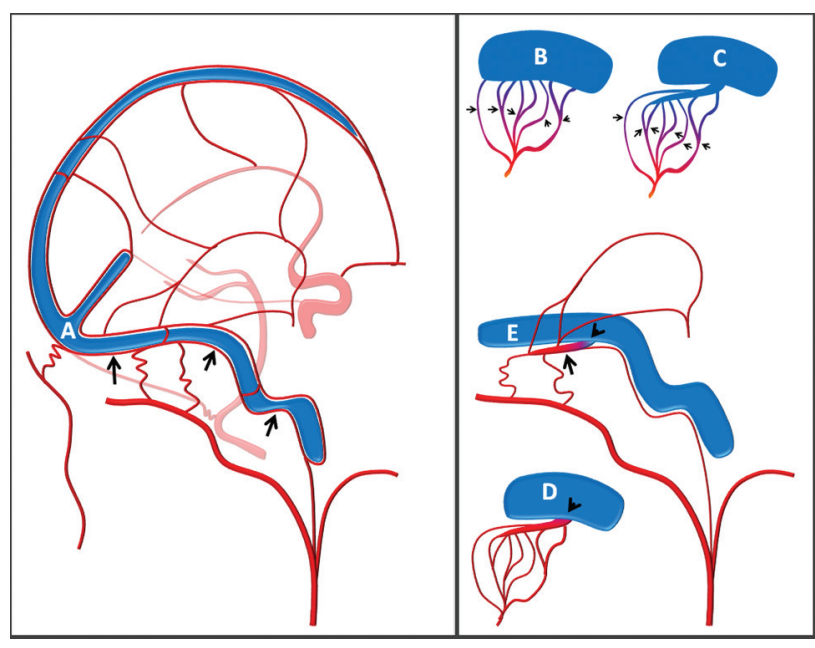

FIG 1. Schematic of normal dural arteriovenous architecture $(A)$, with arrows pointing to the arterial arcade in the wall of the transverse/ sigmoid sinuses. Schematic of dural fistula angioarchitecture according to a view of multiple arteriovenous shunts (black arrows) draining either separately via multiple discrete veins into the sinus $(B)$ or into a common venous collector/pouch/septation (C) alongside the wall of the sinus proper. $D$, A low-grade dural fistula according to the common arterial collector view. Multiple arterial feeders converge on a common arterial channel in the sinus wall that empties into the sinus at a single fistulous point (arrowhead). E, Common arterial collector schematic relative to normal anatomy shown in $A$. The arterial supply converges on the common collector arterial channel within the sinus wall (arrow), with the fistulous point (arrowhead) at the confluence of this channel and the sinus proper.

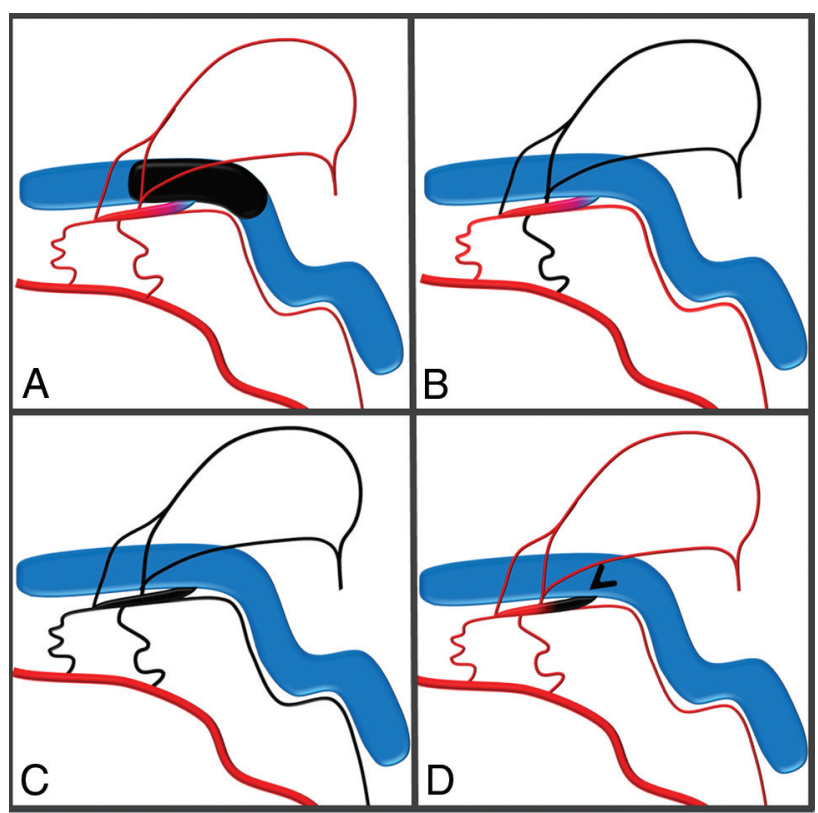

FIG 2. Schematic of typical transvenous sinus sacrifice $(A)$ and incomplete $(B)$ and complete $(C)$ transarterial embolizations, each of which results in an unnecessary closure of arteries or sinus. Targeted occlusion of the shunt $(D)$ at the entrance of the collector channel into the sinus preserves both the sinus and normal arterial structures.

\section{DISCUSSION}

The existence of normal arterial channels within the walls of the dural sinuses is well-described and illustrated in works of Geibprasert el al, ${ }^{9}$ Bernstein and Choi, ${ }^{10}$ Lasjaunias et $\mathrm{al}^{11}$ and others. These vessels comprise distal dural branches of the anterior, mid- 

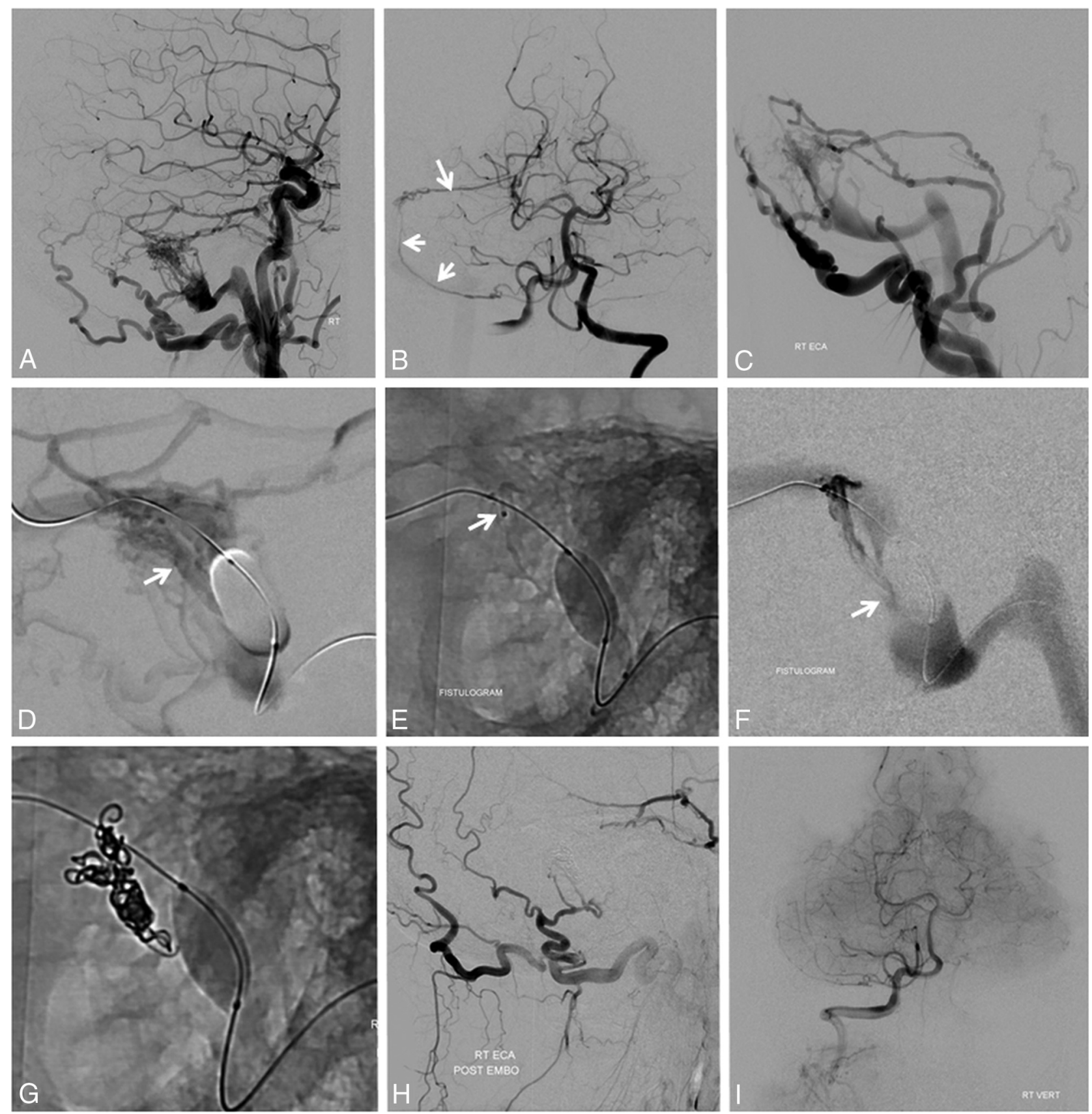

FIG 3. A, Left sigmoid sinus type I dural fistula. Posterior meningeal supply (B) proceeds via arteries in the wall of the transverse/sigmoid sinuses (arrows). Subselective external carotid artery injection $(C)$ shows robust occipital and middle meningeal artery supply. $D$, Inflation of a compliant balloon within the sigmoid sinus reduces transfistulous flow to allow identification of a common collector channel (white arrow) inferior to the sinus proper. $E$ and $F$, Transvenous microcatheterization of a common collector channel ( $E$, distal catheter tip) and subsequent fistulogram ( $F$ ) reduce the fistula to a single point where the collector joins the sinus (white arrow). Subselective coiling of this collector $(G)$ results in fistula closure $(H$ and $I)$.

dle, posterior meningeal, ascending pharyngeal, and occipital arteries, as well as the meningohypophyseal and inferolateral trunks of the internal carotid artery, collectively forming a densely interconnected dural vascular network (Fig 1A). While occasionally visible angiographically in nonpathologic circumstances, the arterial vessels of the dural sinus wall are usually below the threshold of in vivo imaging resolution. They may, however, become angiographically visible in certain pathophysiologic conditions prevailing in the supply of the dAVF, dural-based vascular tumors such as meningiomas, hypertrophied collaterals in cerebral ischemic disease, or following meningeal arterial disruption (postcraniotomy). Close proximity of these arteries to the dural venous sinus and the vast collateral arcades through which they communicate with other dural arterial channels make these vessels a logical common conduit in the angioarchitectural evolution of a sinus dAVF. If we postulate that such a dural wall artery represents a common arterial collector that establishes an abnormal connection with the dural venous sinus to form the dAVF (Fig $1 D,-E$ ), the resulting vasculopathic picture may account for many empirically encountered phenomena related to the angio- 

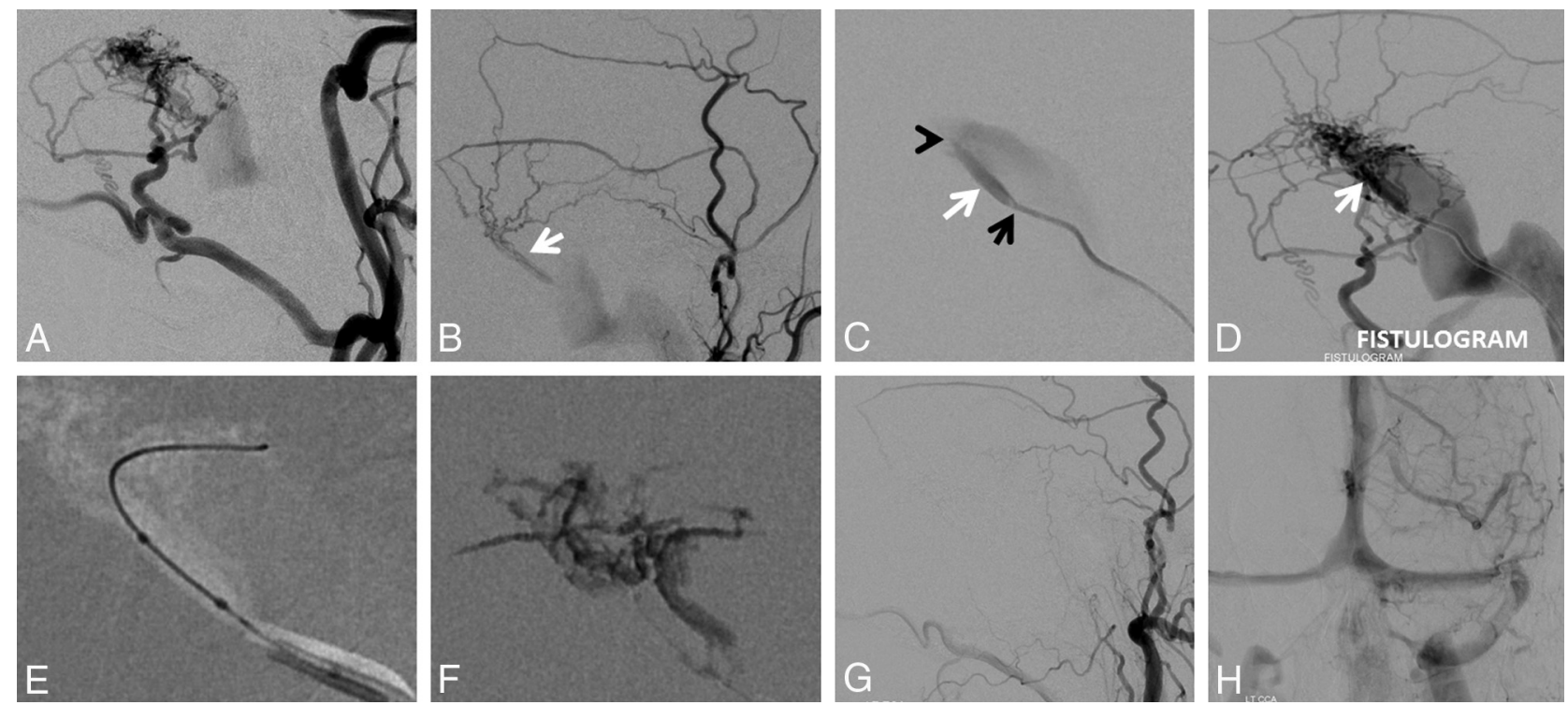

FIG 4. $A$ and $B$, Left type I sigmoid sinus fistula with predominant occipital and middle meningeal supply. C, A 5F VERT (Cook, Bloomington, Indiana) catheter (tip marked by a black arrow) in the sigmoid sinus is wedged into the opening of the common collector (white arrow). Gentle injection of the VERT catheter identifies a second opening of the collector into the sinus shown by the black arrowhead.D, A stronger injection of the VERT (fistulogram) opacifies the entire arterial arcade in a retrograde fashion. E, Scepter C (MicroVention Tustin, California) subselective catheterization of the common collector, with a subsequent $n$-BCA cast in $F$. $G$ and $H$, Postembolization angiography demonstrates occlusion of the fistula with preservation of the left sigmoid sinus.

graphic architecture of dAVFs and the success or failure of various treatment strategies, particularly in lower grade fistulas.

In the classic sigmoid sinus location, this collector is nearly always located inferior to the true sinus, as shown in Figs 1-5. Once its existence is recognized, prospective identification becomes substantially easier, despite the presence of overlapping regional collateral networks that communicate with and supply this common channel, frequently obscuring its detection. The implication of this model is that the true domain of shunting for a dAVF may be, in most cases, simplified to a single site (or small number of sites) where the common arterial channel is connected to the venous sinus rather than an innumerable tangle of arteriovenous shunts along a sinus segment, despite the apparently complex angiographic appearance of the mature lesion.

Literature support for the common collector concept may be found in articles describing the existence of channels alongside the sinus proper, first reported by Mironov ${ }^{12}$ in 1998. Channels parallel to the venous sinus have been accessed successfully via a transvenous route and strategically embolized with coils, producing a durable cure. Piske et $\mathrm{al}^{13}$ in 2005 described cases in which arteriovenous shunting was observed to involve what was described as a sinus compartment, which also could be selectively embolized with main sinus preservation. Similar results were reported earlier by Caragine et al in 2003. ${ }^{14}$ Most recently, Kiyosue et al, ${ }^{15}$ in agreement with our proposal, published results of rotational angiographic evaluation of $25 \mathrm{dAVFs}$, identifying the presence of "shunted pouches" immediately adjacent to the sinus in all 25 cases. Thirteen of these pouches were subselectively embolized via transvenous access, resulting in a durable cure. Baik et $\mathrm{al}^{16}$ reported 8 cases in which a particularly direct arteriovenous connection allowed placement of coils into the venous compartment via the arterial route. These clinical examples each serve to demonstrate that closure of seemingly complex fistulas can be accom- plished by strategic placement of embolic material at the location of the fistula rather than requiring extensive embolization of the innumerable, more proximal, indirect tributaries and strongly support the idea that most dAVFs can be reduced to 1 or a few aberrant arteriovenous communications, the opening of which defines the location of the shunt. In all the above articles, however, these compartments were considered venous. Alternatively, the "common arterial collector" hypothesis proposes that such compartments may represent the final arterial collectors supplying the shunt, rather than venous sinus septations.

For example, the arterial channel within the transverse and sigmoid sinuses most commonly communicates with the sinus at the sigmoid segment. However, the same vessel can develop fistulous connections at the torcular. The resulting complex arrangement that seemingly involves the entire sinus in fact may be reducible to several fistulous connections. At the more proximal end, fistulas involving the jugular bulb can be viewed as a collector artery deriving tributaries from ascending pharyngeal branches.

Several observations made during both transarterial and transvenous treatment approaches support this hypothesis. From transvenous embolizations, we have observed that placement of coils into the sinus may not result in substantial changes in the degree of shunting on control angiography until some critical location in the sinus is reached and the fistula is suddenly closed after placement of a few additional coils-corresponding to what might be expected from ultimate occlusion of a single fistulous site. In many of these transvenous cases, coiling the sinus is accompanied by continued flow immediately adjacent to the sinus coil mass (Fig 5E, -F), likely reflecting persistent patency of the common collector until flow within it is finally arrested when coil embolization reaches the shunting site where this collector opens into the sinus. If this common intradural channel were a vein rather than an artery, it would also be unclear why sacrifice of the 

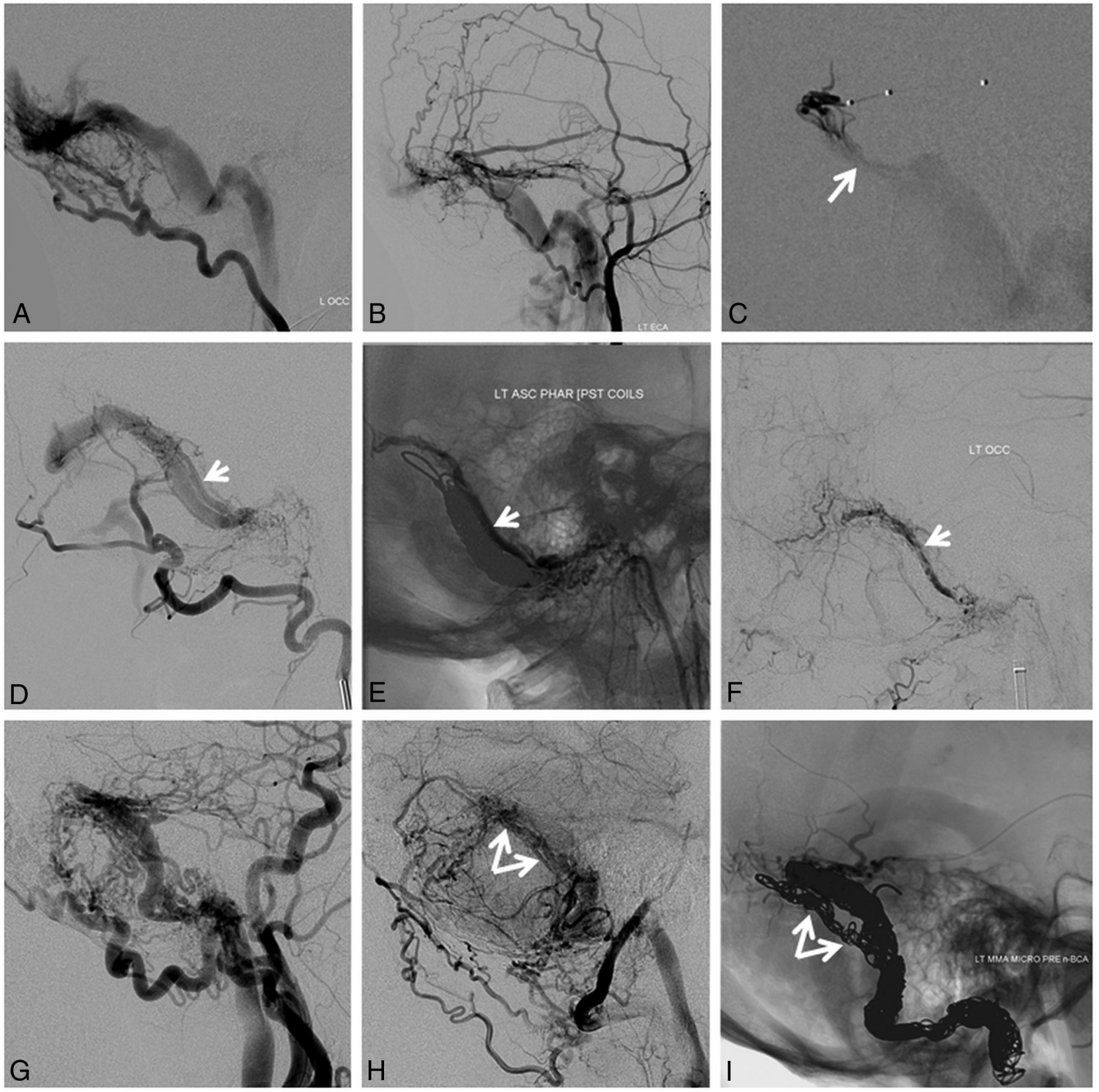

FIG 5. Additional examples of a common collector channel. Case $1(A-C)$ of a type lla fistula shows the collector channel inferior to the sinus (C, white arrow) during Onyx (Covidien, Irvine, California) injection via a Scepter $C$ microcatheter (MicroVention). Case 2 (D-F) illustrates a relatively uncommon presence of a common collector superior to the sinus (white arrows), becoming more obvious after the sinus has been packed with coils. Case $3(G-l)$ is another complex-appearing fistula, where the common collector channel (white arrows) is better seen via the left vertebral contributors $(H)$ due to stenosis of the sinus proper. The collector channel is subsequently filled with coils (I, white arrows). In retrospect, cases 2 and 3 might have been cured by superselective embolization rather than sinus sacrifice.

venous sinus proper should result in a durable cure. Rather, one would expect this kind of embolization to be followed by development of alternative venous outflows, redirecting the drainage of the lesion possibly even into cortical veins. Moreover, the myriad arterial connections to the common channel would represent independent arteriovenous shunts if the channel were a vein, as opposed to collateral arterial-arterial connections if the conduit were the final common dural artery leading to a fistulous connection. If one assumed that the probability of forming an abnormal arteriovenous shunt is $\mathrm{P}$, the likelihood of forming $\mathrm{y}$ independent shunts would be $\mathrm{yP}$, which seems statistically less probable.
Arterial approaches typically require permeation of a liquid embolic into the sinus wall or the sinus itself to be effective. The most common pitfall of arterial embolization in treating dAVFs is a too-proximal deposition of embolic material. While this approach may be used deliberately in a partial or staged embolization, unless the common arterial collector is permeated, this exercise has no direct effect on the fistula, apart from temporary gross total flow reduction. The persistence or recurrence of shunting following proximal arterial embolizations is simply related to continued patency of the common arterial collector and its aberrant arteriovenous communication and inevitably will be fol- 
lowed by enlargement of the remaining arterial routes comprising unembolized collaterals, which may be inaccessible or increasingly hazardous. Treatment succeeds when embolic material permeates the collector and extends to the terminal communication between the collector and the venous sinus, either with occlusion of the sinus or by using more sophisticated, sinus-sparing strategies that use temporary balloon protection of the sinus ${ }^{17}$ or indwelling sinus stents.

As suggested above, the common collector hypothesis is consistent with successful transvenous and transarterial approaches and, in both instances, argues for more selective angiographic identification of the target-shunting site: that location where the common arterial collector (as we consider it, a "septation" or "shunted pouch" opening into the sinus proper, as described by Mironov, ${ }^{12}$ Piske et al, ${ }^{13}$ Caragine et al, ${ }^{14}$ Kiyosue et al, ${ }^{15}$ and others) abnormally communicates with the venous sinus. Identification of this terminal channel potentially allows preservation of the venous sinus proper during treatment and minimizes widespread collateral (nontarget) proximal arterial embolization, reducing the risk to regional cranial nerves.

Nevertheless, the common collector theory can be critiqued on several grounds. In 2 histopathologic studies, Nishigima et $\mathrm{al}^{18}$ and Hamada et $\mathrm{al}^{19}$ concluded that dAVFs consist of myriad microscopic arteriovenous connections within the sinus wall itself, ultimately communicating with the dural sinus (Fig $1 B,-C$ ). As suggested by our statistical argument, however, the development of numerous fistulas, in what appears fundamentally to be a reasonably rare event, seems unlikely. Moreover, Hamada et $\mathrm{al}^{19}$ in their Fig 6 suggest that the final opening of these fistulas into the sinus proceeds via a common channel (which they, however, consider to be a vein) similar to Fig $1 C$ in this article. However, if the fistulas are indeed numerous and located in the sinus wall, there appears to be no need to propose the existence of this common venous collector. From a probability standpoint, it also appears to be more likely that fistulas should be few rather than many if the entire angioarchitecture can be thus accounted for-an example of the Ockham razor. Additionally, from a histologic perspective, the existence of discrete mural veins that extend along the entire length of the dural venous sinuses under nonpathologic conditions has not been described, to our knowledge, while such arterial channels within the sinus walls are well-recognized. From the standpoint of the disease pathogenesis, if we hold that at least some dAVFs form because of sinus thrombosis and its subsequent lysis, ${ }^{20}$ it seems more plausible that various lytic agents would act on the inner sinus wall to induce an aberrant arteriovenous connection between the sinus and an adjacent dural wall artery rather than establish myriad fistulous connections with the sinus itself or a parallel venous channel within the sinus wall.

Objection to the common arterial collector hypothesis may arise from apparent difficulty in defining this "common conduit" on routine angiography. However, the region of even relatively simple fistulas is often quite "busy" angiographically, and consistent identification of this channel is hampered by difficulty in its uniform opacification from 1 angiographic source in the face of competing unopacified inflow and overlap of the myriad collateral vessels, obscuring the underlying dAVF angioarchitecture. Some may find it counterintuitive to consider a terminal larger caliber vessel representing a collecting artery rather than vein. It is nevertheless a pathophysiologically coherent arrangement, accounting for collaterally fed high-flow networks. For example, proximal ligation of large vessels such as the external carotid or vertebral arteries frequently leads to reconstitution of their distal territory via multiple individually smaller-sized collaterals with maintenance of the original vessel caliber of the reconstituted segment.

Another critique concerns our inability to consistently identify collector channels in higher grade lesions. We postulate that this stems from the extensive asymmetric obliteration of normal anatomic structures in high-grade lesions, many of which are associated with narrowing or thrombosis of the native venous sinus. When the recipient sinus is occluded both retrograde and antegrade to the fistula, the common collector may come to drain through a trapped sinus segment (of variable dimensions) into regional cortical veins. This may limit the utility of subselective common collector embolization to anatomically lower grade lesions, many of which may be characterized by a more favorable natural history, and, instead, may be reasonably observed. ${ }^{7,21} \mathrm{We}$ agree, yet believe that subselective embolization of a common channel via a transvenous approach (Figs 3 and 4) is safe, effective, and elegant and that a good proportion of type IIa lesions also appear to have a common collector target. We do not believe that all common collectors can be embolized; for example, the collector may be too short or tortuous to allow subselective catheterization. Indeed, most of our cases were cured by transarterial embolization or sinus sacrifice.

The generalizability of the theory can be questioned on the basis of our exclusion of more complex fistulas of other sites (cavernous sinus, superior petrosal sinus, and torcular) from the analysis; however, observations reported by Satow et $\mathrm{al}^{22}$ for cavernous sinus dural fistulas suggest the applicability of the principle in other settings. Volumetric imaging methods may be useful for better appreciation of the unique angioarchitecture in these areas.

Finally, the proposed model may be too simplistic, considering the variety of fistulas encountered in practice. The common arterial collector, like any theory, is open to the possibility of exceptions, variations, refutation, and improvement. It is our view that it represents an advance in our understanding of dAVF angioarchitecture and is useful as a guide to treatment.

\section{CONCLUSIONS}

The seemingly complex lateral sinus dAVF angioarchitecture may be reduced in many instances to 1 or several discrete aberrant arteriovenous communications between arteries in the wall of the dural sinus and the sinus lumen itself. In the described model, an enlarged mural artery serves as the final common conduit supplying a simple fistulous site. This common arterial collector, in turn, receives the collective arterial inflow to the fistula through its numerous arterial anastomoses with an extensive collateral network, accounting for the convergence of myriad dural arteries near the region of shunting. Highly targeted occlusion of these artery-tosinus communications allows occlusion of the shunt with sinus preservation and reduced inadvertent embolization of vessels not directly involved in the pathologic arteriovenous shunt.

AJNR Am J Neuroradiol 39:1682-88 Sep 2018 www.ajnr.org 
Disclosures: Eytan Raz-UNRELATED: Consultancy: Medtronic; Royalties: Springer; Stock/Stock Options: Stryker and Penumbra; Travel/Accommodations/Meeting Expenses Unrelated to Activities Listed: Medtronic, MicroVention. Peter K. NelsonRELATED: Consulting Fee or Honorarium: Medtronic, Comments: fees for clinical proctoring. Maksim Shapiro-UNRELATED: Consulting Fee or Honorarium: Medtronic, Comments: fees for clinical proctoring.

\section{REFERENCES}

1. Borden JA, Wu JK, Shucart WA. A proposed classification for spinal and cranial dural arteriovenous fistulous malformations and implications for treatment. J Neurosurg 1995;82:166-79 CrossRef Medline

2. Cognard C, Gobin YP, Pierot L, et al. Cerebral dural arteriovenous fistulas: clinical and angiographic correlation with a revised classification of venous drainage. Radiology 1995;194:671-80 CrossRef Medline

3. Hu YC, Newman CB, Dashti SR, et al. Cranial dural arteriovenous fistula: transarterial Onyx embolization experience and technical nuances. J Neurointerv Surg 2011;3:5-13 CrossRef Medline

4. Kim DJ, Willinsky RA, Krings $\mathrm{T}$, et al. Intracranial dural arteriovenous shunts: transarterial glue embolization-experience in $\mathbf{1 1 5}$ consecutive patients. Radiology 2011;258:554-61 CrossRef Medline

5. Roy D, Raymond J. The role of transvenous embolization in the treatment of intracranial dural arteriovenous fistulas. Neurosurgery 1997;40:1133-41; discussion 1141-1134 CrossRef Medline

6. Lekkhong E, Pongpech S, Ter Brugge K, et al. Transvenous embolization of intracranial dural arteriovenous shunts through occluded venous segments: experience in $\mathbf{5 1}$ patients. AJNR Am J Neuroradiol 2011;32:1738-44 CrossRef Medline

7. Cognard C, Januel AC, Silva NA Jr, et al. Endovascular treatment of intracranial dural arteriovenous fistulas with cortical venous drainage: new management using Onyx. AJNR Am J Neuroradiol 2008;29:235-41 CrossRef Medline

8. McConnell KA, Tjoumakaris SI, Allen J, et al. Neuroendovascular management of dural arteriovenous malformations. Neurosurg Clin N Am 2009;20:431-39 CrossRef Medline

9. Geibprasert S, Pereira V, Krings T, et al. Dural arteriovenous shunts: a new classification of craniospinal epidural venous anatomical bases and clinical correlations. Stroke 2008;39:2783-94 CrossRef Medline
10. Berenstein A, Choi IS. Surgical neuroangiography of intracranial lesions. Radiol Clin North Am 1988;26:1143-51 Medline

11. Lasjaunias PL, Berenstein A, Ter Brugge KG. Surgical Neuroangiography. Berlin: Springer-Verlag; 2001

12. Mironov A. Selective transvenous embolization of dural fistulas without occlusion of the dural sinus. AJNR Am J Neuroradiol 1998; 19:389-91 Medline

13. Piske RL, Campos CM, Chaves JB, et al. Dural sinus compartment in dural arteriovenous shunts: a new angioarchitectural feature allowing superselective transvenous dural sinus occlusion treatment. AJNR Am J Neuroradiol 2005;26:1715-22 Medline

14. Caragine LP, Halbach VV, Dowd CF, et al. Parallel venous channel as the recipient pouch in transverse/sigmoid sinus dural fistulae. $\mathrm{Neu}$ rosurgery 2003;53:1261-66; discussion 1266-67 CrossRef Medline

15. Kiyosue H, Tanoue S, Okahara M, et al. Angioarchitecture of transverse-sigmoid sinus dural arteriovenous fistulas: evaluation of shunted pouches by multiplanar reformatted images of rotational angiography. AJNR Am J Neuroradiol 2013;34:1612-20 CrossRef Medline

16. Baik SK, Kim YW, Lee SW, et al. A treatment option for nontraumatic adult-type dural arteriovenous fistulas: transarterial venous coil embolization. World Neurosurg 2014;82:417-22 CrossRef Medline

17. Shi ZS, Loh Y, Duckwiler GR, et al. Balloon-assisted transarterial embolization of intracranial dural arteriovenous fistulas. J Neurosurg 2009;110:921-28 CrossRef Medline

18. Nishijima M, Takaku A, Endo S, et al. Etiological evaluation of dural arteriovenous malformations of the lateral and sigmoid sinuses based on histopathological examinations. J Neurosurg 1992;76: 600-06 CrossRef Medline

19. Hamada Y, Goto K, Inoue T, et al. Histopathological aspects of dural arteriovenous fistulas in the transverse-sigmoid sinus region in nine patients. Neurosurgery 1997;40:452-56; discussion 456-58 Medline

20. Houser OW, Campbell JK, Campbell RJ, et al. Arteriovenous malformation affecting the transverse dural venous sinus: an acquired lesion. Mayo Clin Proc 1979;54:651-61 Medline

21. Söderman M, Pavic L, Edner G, et al. Natural history of dural arteriovenous shunts. Stroke 2008;39:1735-39 CrossRef Medline

22. Satow T, Murao K, Matsushige T, et al. Superselective shunt occlusion for the treatment of cavernous sinus dural arteriovenous fistulae. Neurosurgery 2013;73(1 Suppl Operative):ons 100-05 CrossRef Medline 